\title{
Uma proposta para a modelagem do valor percebido na prestação de serviços
}

\author{
Paulo Ricardo Ckless Silva \\ Scherer Informática. \\ E-mail:pckless@schererinformatica.com.br \\ José Luis Duarte Ribeiro, Dr. \\ Programa de Pós-Graduação em Engenharia de Produção, UFRGS. \\ E-mail: ribeiro@ufrgs.br
}

\section{Resumo}

Este trabalho apresenta uma proposta para a modelagem do valor percebido na prestação de um serviço. Conhecido o valor percebido, é possível compará-lo com os custos do serviço, estabelecendo uma base para o planejamento das ações de melhoria e para a priorização das atividades que oferecem maior lucratividade. A modelagem proposta é ilustrada através de um estudo de caso contemplando o setor de serviços de manutenção em computadores pessoais.

Palavras-chave

Serviços, Valor percebido, Custos, Rentabilidade.

\section{A proposal for modeling service perceived value}

\begin{abstract}
This paper presents a proposal for modeling the perceived value associated to a service. Once the perceived value is known, it is possible to perform a comparison with the corresponding costs. This comparison forms the base for the establishment of an improvement plan and allows the prioritization of the activities showing higher profitability. The proposed model is illustrated through a case study conducted on the personal computers maintenance sector.
\end{abstract}

Key words

Service, Perceived value, Costs, Profitability. 


\section{INTRODUĈ̣̃O}

O mercado de serviços mostra-se promissor para as empresas que acompanham as alterações na economia global. O atendimento da expectativa do cliente é uma das chaves para obter sucesso frente à concorrência. Tecnologias como o CRM (customer relationship management) têm a finalidade de descobrir o que satisfaz o cliente e, com base nos resultados de pesquisas, estabelecer em que dimensões a gerência deve aportar recursos para a obtenção de desempenho superior (AUSTIN, 2000).

As tendências atuais indicam que a tecnologia continuará disponibilizando informações que facilitam o gerenciamento dos aspectos importantes para o cliente. No entanto, continuará sendo fundamental a avaliação do retorno financeiro que diferentes medidas proporcionam à organização. Em função da crescente competitividade, observada em todos os setores da economia, as margens de lucro serão menores, os riscos serão maiores, reforçando a importância do entendimento do valor que um produto pode agregar ao cliente e à organização.

Este trabalho apresenta uma modelagem para a determinação do valor percebido pelo cliente associado a diferentes serviços e níveis de serviços que podem ser ofertados. A modelagem proposta permite equacionar melhor $\mathrm{o}$ atendimento das expectativas do cliente e, simultaneamente, a lucratividade da organização. Sem dúvida, é crescente o número de empresas que buscam melhorar continuamente a qualidade de seus serviços. Existe um consenso relativo à necessidade de buscar a excelência na prestação de serviços. O estudo das expectativas do cliente, do valor atribuído ao atendimento dessas expectativas e da rentabilidade associada, auxilia a conectar o cliente às estratégias da empresa, levando a melhor distribuição dos recursos de que as organizações dispõem.

Após essa introdução, apresenta-se uma revisão bibliográfica referente à avaliação das expectativas dos clientes. Uma breve descrição da técnica conhecida por estudos em Grupo Focalizado, uma vez que essa técnica é usada no estudo de caso e não é do conhecimento de todos. Apresenta-se a modelagem proposta em seguida, a qual será explicada através de um estudo de caso. O desenvolvimento do estudo de caso é apresentado, contemplando o levantamento dos atributos valorizados pelo cliente, a modelagem matemática e as ações empreendidas após a análise dos resultados. Por fim, apresentam-se as conclusões do artigo.

\section{AVALIAC̣̃̃O DAS EXPECTATIVAS DOS CLIENTES}

Para Fisher \& Saliba (2000), a natureza subjetiva das decisões gerenciais, efetuadas a partir de informações incompletas e incertezas, fazem crescer a importância de definir os atributos valorizados pelos clientes, de modo a entender todos os benefícios e dificuldades que os consumidores consideram antes de efetuar a compra. Conhecendo esses aspectos, o gerente pode desenvolver melhor a sua estratégia para aumentar o valor de seus produtos, partindo da perspectiva de clientes atuais ou potenciais.

\section{as margens de lucro serão menores, os riscos serão maiores, reforçando a importância do entendimento do valor que um produto pode agregar ao cliente e à organização.}

Segundo Berry \& Parasuraman (1992), um fator primordial e determinante na qualidade dos serviços prestados é a discrepância entre expectativas e impressões na avaliação dos clientes. A expressão expectativa tem dois sentidos diferentes - aquilo que os consumidores acreditam que ocorrerá quando se defrontam com um serviço (previsões) e aquilo que eles esperam que aconteça (desejos) - não existindo formulação conceitual para integrar as expectativas e a compreensão de sua influência na avaliação dos serviços prestados ao cliente.

Berry \& Parasuraman (1992) afirmam que o mais antigo axioma do marketing é conhecer o cliente e quais são as suas necessidades. Eles acrescentam que os empregados também são clientes e devem ser pesquisados e tratados dessa forma. O planejamento de produto-trabalho que atraia, desenvolva, motive e retenha esses clientes demanda muita sensibilidade referente às aspirações, atitudes e preocupações dos empregados. Em geral, os gerentes pressupõem equivocadamente determinadas posições por parte dos trabalhadores. A prática da pesquisa interna é tão importante quanto a da pesquisa externa.

Conforme Barcellos (1999), para medir a satisfação do cliente, pode-se utilizar o método direto ou o indireto, 
porém o mais adequado é utilizar ambos os procedimentos, tendo em vista a complementaridade dos mesmos. A vantagem do levantamento direto, que contempla questões objetivas formuladas aos clientes, é a possibilidade de investigar produtos que ainda não foram oferecidos, ou recém-lançados no mercado. No entanto, esse método pressupõe a existência de uma correspondência direta entre a satisfação do cliente e suas respostas às questões. A vantagem do levantamento indireto, que contempla a investigação do comportamento do cliente referente a reclamações e repetição de compras, é que esse método baseia-se no comportamento observado, o qual revela de forma inequívoca a satisfação do cliente.

Segundo Gustafsson \& Johnson (1997), aumentar a satisfação dos clientes requer que a empresa se organize, estabelecendo uma conexão entre a qualidade dos processos internos e as percepções de qualidade e satisfação dos clientes, envolvendo um importante e complexo processo de translação. Melhorias na qualidade representam custos, a menos que elas afetem as percepções de satisfação e o comportamento de compra dos clientes. Gustafsson \& Johnson (1997) concluem que as medições e priorizações das necessidades dos clientes devem distinguir entre atributos de produtos e serviços que se constituem em variáveis observáveis, e outros benefícios que interferem na satisfação geral dos clientes, mas que se constituem em variáveis latentes ou não observáveis. Procedimentos empíricos e teóricos podem oferecer meios para associar as variáveis observáveis e não observáveis, as quais provêm as informações necessárias para priorizar as melhorias de qualidade.

Carlzon (1994) afirma surpreender-se com alguns executivos que começam pelo planejamento de objetivos e estratégias sem antes terem escutado seus clientes, precisando, mais tarde, regressar para examinarem as necessidades dos usuários. Grönroos (1996) indica que a qualidade de um serviço, como percebida pelos clientes, possui duas dimensões: a técnica, que é relacionada às conseqüências do que o cliente recebe em suas interações com as empresas; e a funcional, que é relacionada ao processo, ou seja, à forma como os clientes recebem o serviço e experimentam a sua produção, durante as horas da verdade. Para que os investimentos nos negócios valham a pena, é necessário desenvolver os atributos desejados pelos clientes. Identificar, explicitar e medir os requisitos dos clientes são ações essenciais na construção de qualidade superior.

Com o advento da Internet, os consumidores passaram a dialogar ativa e explicitamente com fornecedores de bens e serviços. Segundo Prahalad \& Rasmawany (2000), não é fácil aproveitar as competências do consumidor para aumentar a competitividade no negócio. Inicialmente a empresa deve dominar quatro realidades fundamentais para poder aproveitar as competências. A organização deverá engajar seus clientes em um diálogo ativo, claro e constante; deverá mobilizar comunidades de consumidores; deverá administrar as diferenças entre eles; e, por fim, deverá criar experiências personalizadas junto com os clientes.

Para Prahalad \& Rasmawany (2000), a nova economia exige a reforma dos sistemas tradicionais de gestão e das estruturas organizacionais. Essa reforma é essencial para que as organizações possam aproveitar as competências dos clientes. Os padrões da nova economia devem levar em conta o capital intelectual que existe tanto na força de trabalho como nos próprios clientes. Os princípios contábeis adotados por todas as empresas foram projetados para negócios estáveis, onde eram privilegiados os ativos fixos, tais como: estoque, terrenos e instalações físicas. A competência dos consumidores é um ativo intangível e deve ser tratada como capital e não como um ativo fixo.

Edvinsson \& Malone (1998) sugerem que compreender seus ativos intangíveis constitui fator crítico para o sucesso das empresas modernas. A posse desse conhecimento permite à organização saber quais são os seus pontos fortes, e acioná-los rapidamente, em um ambiente competitivo caracterizado por constante mutação. Também possibilita, por outro lado, o conhecimento dos pontos fracos, permitindo que eles sejam eliminados, antes que os mesmos venham a causar problemas operacionais. Albrecht (1992) observa que o fortalecimento do setor de serviços, na economia atual, em parte, deve-se ao fato de os relacionamentos serem, hoje, mais importantes que os produtos físicos. Assim como os americanos tiveram a revolução industrial, na virada do século XIX para o século XX, agora nós estamos vivendo a revolução dos serviços.

Tendo em vista a revisão apresentada, fica evidente que as empresas devem buscar a maximização do lucro, estruturando suas ações a partir do valor percebido pelos clientes. O objetivo de maior rentabilidade será obtido se a empresa priorizar suas atividades e investimentos segundo as orientações do cliente e do mercado onde ela atua.

\section{GRUPO FOCALIZADO}

Segundo Beyea \& Nicoll (2000), estudos em grupos focalizados são fóruns de pequenos grupos de pessoas reunidos por aproximadamente duas horas para apresentar suas opiniões sobre determinado assunto. O estudo é conduzido por um moderador, que utiliza um roteiro de entrevista semi-estruturada para gerar as discussões. É seu papel saber como formular as perguntas, explorar informações, fazer com que os membros do grupo sintam-se à vontade para partilhar suas opiniões e fazer com 
que todos os participantes opinem. Como em todo esforço de coleta de dados, a qualidade da informação obtida depende diretamente da qualidade do planejamento e da implementação que ocorrem antes e durante a sessão do grupo focalizado. Os estudos em grupos focalizados exploram a influência de uma pessoa sobre as demais.

Omerod apud Bennekon (2000) argumenta que os seres humanos são claramente influenciados pelos outros. Basta verificar como as decisões de compra de estoques são tomadas, ou como a cada Natal um novo brinquedo tornase o brinquedo da moda. O comportamento dos outros influencia a decisão, que algumas vezes foge do que seria esperado a partir de um ponto de vista racional. A economia tradicional falha neste ponto, porque tem uma premissa de equilíbrio competitivo. Os indivíduos não agem isoladamente, e o marketing pode realmente modificar o comportamento de grupos de pessoas. "A sociedade é como um organismo vivo - uma criatura viva, cujo comportamento somente pode ser entendido olhando as interações complexas entre os seus indivíduos e suas partes."

Omerod apud Bennekon (2000) também afirma que a teoria do caos, tal qual a teoria quântica, mostra que os eventos são interconectados e imprevisíveis. Um pequeno evento pode ter grandes conseqüências, e grandes eventos podem ter consequiências menores. Talvez a parte mais importante de um sistema seja o ponto de início, mas os eventos acontecem randomicamente e são difíceis de prever. "A imprevisibilidade é parte inerente do processo, o qual consubstancia um largo espectro de fenômenos sociais e econômicos."

$\mathrm{O}$ aspecto de imprevisibilidade existe nos grupos focalizados, visto que ninguém pode prever o que acontecerá numa reunião de um grupo representativo de uma sociedade. Não se sabe como vão se relacionar pessoas de diferentes perfis e formação. A interação entre elas pode ser de grande valia na pesquisa. De certa forma, o grupo focalizado mimetiza a imprevisibilidade estudada na teoria do caos e na teoria quântica, mencionada pelos autores citados anteriormente.

Ribeiro \& Ruppenthal (2000) postulam que os grupos focalizados propiciam riqueza e flexibilidade na fase de coleta de dados, ao contrário do que acontece quando se aplica um instrumento de pesquisa individual, onde o respondente restringe-se ao seu próprio conhecimento e experiências. Os estudos em grupo focalizado também costumam facilitar a espontaneidade dos participantes, desperta- da a partir da interação entre indivíduos de diferentes formações.

Esses autores enumeram as seguintes vantagens dos estudos em grupos focalizados: (i) possibilidade de coletar dados em um pequeno espaço de tempo, caracterizando um método rápido, econômico e eficiente para obter informações; (ii) a experiência de grupo geralmente é positiva, facilitando a discussão dos assuntos e incentivando a participação de todos; (iii) alguns indivíduos claramente preferem esse ambiente, pois acham apoio em outros membros do grupo e, assim, ganham coragem para expressar suas idéias; (iv) os membros do grupo têm a possibilidade de

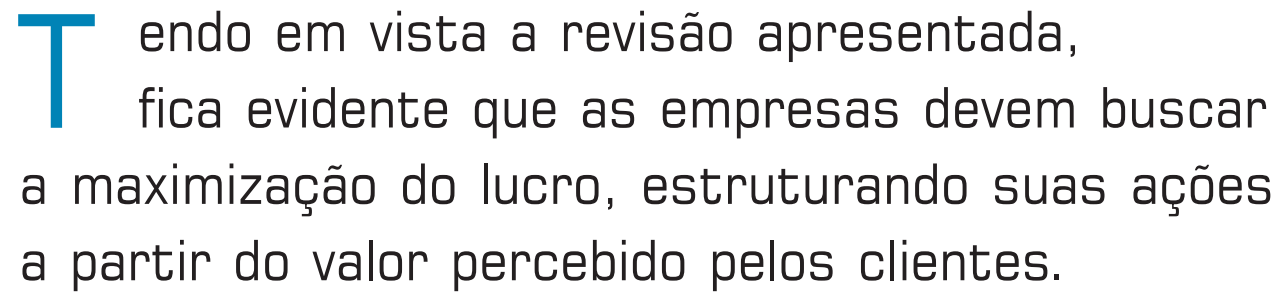

ouvir diversos pontos de vista, podendo qualificar suas próprias respostas; (v) grande possibilidade de validação dos dados, pois a qualquer momento pode se solicitar ao grupo para confirmar alguma informação crítica; (vi) baixo custo comparado a outros métodos de pesquisa qualitativa (entrevistas individuais, observação passiva, etc.); (vii) facilidade de aumentar o tamanho da amostra, quando necessário, pois os estudos podem ser replicados (mesmo roteiro, novo grupo de pessoas) ou ampliados (mesmo grupo, novas sessões e roteiro).

\section{MODELAGEM PROPOSTA}

A modelagem proposta contempla o levantamento dos atributos valorizados pelos clientes, seguido de modelagem matemática e definição de ações para reforçar a competitividade empresarial. A abordagem pode ser organizada em sete etapas principais:

1. Levantamento dos atributos de interesse para o cliente (por exemplo, Velocidade de Atendimento), os quais serão chamados genericamente de $X_{1}, X_{2}, \ldots, X_{k}$. No estudo de caso que será detalhado a seguir, esses atributos foram levantados junto aos clientes, no primeiro encontro do grupo focalizado.

2. Levantamento dos níveis de qualidade característicos para cada atributo, ou seja, intervalo de valores possíveis para $X_{1}, \ldots, X_{k}$. Por exemplo, os níveis de velocidade de atendimento podem ser rápido (2 horas), normal (seis horas) ou lento (24 horas). Novamente, no estudo de caso 
que será apresentado, os intervalos foram definidos com o apoio dos clientes, durante o primeiro encontro do grupo focalizado.

3. Levantamento do valor atribuído pelo cliente para os diversos atributos e seus respectivos níveis. Por exemplo, se o atendimento for rápido, o cliente pode estar disposto a pagar uma mensalidade de $\mathrm{R} \$ 37,00$; contudo, se o atendimento for lento, o cliente está disposto a pagar $\mathrm{R} \$ 21,00$. No estudo de caso em questão, esse foi o tema do segundo encontro do grupo focalizado.

4. Estabelecimento de um modelo matemático para o valor percebido pelo cliente associado aos serviços que podem ser oferecidos. Esse modelo é construído ouvindo o cliente, a partir das informações obtidas na etapa 3.

5. Estabelecimento de um modelo matemático para os custos dos serviços que podem ser oferecidos. Esse modelo é obtido junto à equipe técnica, a partir das informações contidas nas planilhas de custo da empresa.

6. Comparação entre o valor percebido e os custos, avaliando o potencial de lucro associado aos níveis de prestação de serviços que podem ser oferecidos. Essa comparação é feita utilizando os modelos desenvolvidos nas etapas 4 e 5.

7. Empreender ações em função dos resultados obtidos. A etapa 6, que compara valor percebido e custos, revela modalidades e níveis de prestação de serviços que apresentam maior e menor potencial de lucro. Em função desses resultados, a empresa pode definir várias ações que irão reforçar a sua competitividade.

Essas etapas serão explicadas em maior detalhe na seqüência, juntamente com o relato de um estudo de caso.

\section{ESTUDO DE CASO}

\section{Apresentação do estudo de caso}

A empresa pesquisada iniciou atividades em 1993, com proposta de atuação na manutenção de computadores. Sua atuação ocorre tanto na Capital (Porto Alegre) como no interior do Estado. Originada pela necessidade de terceirização deste tipo de serviço, foi formada por ex-funcionários da Proceda, empresa que era o braço de informática do grupo Bunge. A organização apresenta estilo de administração participativa, estando o capital social dividido entre oito sócios. Apresenta atualmente um faturamento médio de $\mathrm{R} \$ 100.000,00$ (cem mil reais) mensais, atuando no atendimento à pessoa física e ao mercado corporativo nas pequenas e médias empresas, com manutenção de Hardware e suporte em Softwares. Possui uma carteira de clientes diversificada. Atende nas modalidades de contrato (com ou sem técnicos residentes) ou atendimento avulso: na empresa ou domicílio do cliente, com hora marcada. Apresenta um balcão de serviços diferenciado, com atendimento expresso em casos emergenciais.

\section{Levantamento dos atributos valorizados pelo cliente}

O levantamento das expectativas dos clientes foi feito a partir de fontes primárias de informação, ou seja, junto aos próprios clientes. Para fazer o levantamento, foi utilizado o método de pesquisa conhecido como grupo focalizado. $\mathrm{O}$ público alvo foi sugerido pela empresa com a finalidade de estudar variações em um mercado em que a empresa pretende aumentar sua participação: o mercado de varejo, ou SOHO (Small Office Home Office), como é conhecido no meio de informática.

Inicialmente definiu-se que o produto a ser pesquisado seria o contrato de serviços, o qual é composto de diversos atributos, sugeridos pelos próprios clientes pesquisados.

$\mathrm{Na}$ escolha dos componentes dos grupos focalizados buscou-se formar um grupo de grande diversidade, capaz de representar as diferenças que existem na população alvo. Assim, foram consideradas três variáveis: idade, sexo e perfil profissional. Definiu-se que os participantes deveriam ser clientes da empresa, pertencendo a três perfis profissionais: empreendedor (qualquer profissão), ciências exatas (engenharia, contabilidade, matemática) e ciências humanas (administração, medicina, enfermagem, psicologia). O Quadro 1 apresenta o perfil das nove pessoas convidadas para participar do estudo.

No planejamento do estudo em grupo focalizado, estabeleceu-se que ele seria conduzido em dois encontros. No primeiro encontro, os objetivos foram estabelecer quais os atributos desejados pelos clientes (representados pelos componentes do grupo); no segundo encontro, o objetivo foi quantificar o valor atribuído pelo cliente aos diversos atributos, tendo em vista os diferentes níveis de prestação de serviços que podem ser oferecidos.

As questões elaboradas com a finalidade de guiar o primeiro evento foram apresentadas ao grupo focalizado. As perguntas foram apresentadas na seguinte seqüência: as duas primeiras contemplam uma abordagem inicial, para situar as pessoas no âmbito da pesquisa; as três perguntas subseqüentes têm a finalidade de descobrir os atributos que os participantes valorizam; a questão seguinte tem a finalidade de descobrir os níveis dos atributos que seriam adequados; e as duas últimas investigam serviços complementares, que poderiam ser valorizados pelos clientes. O roteiro utilizado foi o seguinte:

- Como seus colegas se relacionam com computadores? Amam, odeiam, suportam, dependem de?

- O que seus colegas entendem de computadores? Muito, pouco, quase nada? Eles sabem quem é o Bill Gates? Eles sabem a diferença entre o Word e o Excel? Eles sabem o que é um banco de dados relacionados? Conhecem rede? 
- Qual o tipo de suporte em Hardware e Software que você acha que eles precisam?

- Quais os tipos de serviços que são oferecidos e que vocês acham que são importantes?

- Quais os tipos de serviços que não são oferecidos e que poderiam ser importantes?

- Para cada tipo de serviço identificado, qual o nível de prestação de serviço que seria adequado para seus colegas?

- Quais as características que você mais aprecia na empresa X?

- Quais as áreas que você acredita que poderiam melhorar na empresa $\mathrm{X}$ ?

O primeiro encontro do estudo em grupo focalizado permitiu que fossem identificados os atributos de interesse para o cliente. Os atributos foram identificados a partir das respostas fornecidas pelos participantes, as quais foram organizadas e sumarizadas pelos autores desse trabalho, contando com o auxílio da equipe técnica da empresa em estudo. Esses atributos serão designados por $\mathrm{X}_{1}, \mathrm{X}_{2}, \ldots \ldots, \mathrm{X}_{14}$

\section{Levantamento dos níveis de qualidade}

Conhecidos os atributos valorizados pelos clientes, e utilizando subsídios tanto do grupo focalizado como da equipe técnica da empresa, foram definidos os níveis de prestação de serviço, ou seja, o intervalo de valores possíveis para cada atributo. Os atributos identificados e os respectivos intervalos aparecem na Tabela 1.

\section{Quadro 1: Perfil dos participantes do Grupo Focalizado.}

\begin{tabular}{|c|c|c|c|}
\hline & Menor do que 30 anos & Entre 30 e 45 anos & Maior do que 45 anos \\
\hline Ciências exatas & $\begin{array}{c}\text { Contador } \\
\text { Masculino } \\
\text { Entrevistado } 1\end{array}$ & $\begin{array}{l}\text { Matemática } \\
\text { Feminino } \\
\text { Entrevistado } 2\end{array}$ & $\begin{array}{c}\text { Sistemas } \\
\text { Feminino } \\
\text { Entrevistado } 3\end{array}$ \\
\hline Ciências humanas & $\begin{array}{c}\text { Advogado } \\
\text { Masculino } \\
\text { Entrevistado } 4\end{array}$ & $\begin{array}{l}\text { Médico } \\
\text { Masculino } \\
\text { Entrevistado } 5\end{array}$ & $\begin{array}{l}\text { Enfermeira } \\
\text { Feminino } \\
\text { Entrevistado } 6\end{array}$ \\
\hline Empreendedor & $\begin{array}{c}\text { Psicologia } \\
\text { Feminino } \\
\text { Entrevistado } 7\end{array}$ & $\begin{array}{c}\text { Dentista } \\
\text { Masculino } \\
\text { Entrevistado } 8\end{array}$ & $\begin{array}{l}\text { Administrador } \\
\text { Masculino } \\
\text { Entrevistado } 9\end{array}$ \\
\hline
\end{tabular}

Tabela 1: Classificação dos atributos e seus níveis de qualidade.

\begin{tabular}{|c|c|c|c|}
\hline & Atributo & Tipo de variável & Intervalo (niveis) \\
\hline$X_{1}$ & Tipo de atendimento & Discreta & Balcão, Telebusca ou On-site \\
\hline$x_{2}$ & Tipo de cobertura & Discreta & Hardware, Software ou H \& S \\
\hline$X_{3}$ & Velocidade de atendimento & Contínua & 1 a 48 horas \\
\hline$X_{4}$ & Assistência com hora marcada & Contínua & $0=$ não, $1=\operatorname{sim}$ \\
\hline$X_{5}$ & Disponibilidade do atendimento & Contínua & 8 a 24 horas \\
\hline$X_{6}$ & Qualificação dos técnicos & Contínua & $0=$ baixa, $1=$ alta \\
\hline$x_{7}$ & Explicações detalhadas & Contínua & 0 = não, 1 = muito detalhada \\
\hline$x_{8}$ & Disponibilidade de teleajuda & Contínua & 0 a 24 horas/dia \\
\hline$X_{9}$ & Tempo de acesso ao teleajuda & Contínua & 1 a 20 horas/mês \\
\hline$X_{10}$ & Treinamento & Contínua & 0 a 24 horas/ano \\
\hline $\mathrm{X}_{11}$ & Suporte na aquisição & Discreta & $\begin{array}{l}\text { Nenhum, Cotação, Cotação + Projeto, } \\
\text { Cotação + Projeto + Pró-ativo }\end{array}$ \\
\hline$X_{12}$ & Auto-ajuda via Internet & Discreta & Nenhuma, Hardware, Software, H \& S \\
\hline$X_{13}$ & Instalação de Hardware e Software & Discreta & Sem suporte, Hardware, Software, H \& S \\
\hline$X_{14}$ & Instalação com hora marcada & Contínua & 0 = não, 1 = sim \\
\hline
\end{tabular}




\section{Levantamento do valor percebido}

No segundo encontro, os entrevistados responderam a questões pertinentes às expectativas que eles haviam demonstrado no primeiro encontro. Eles foram instados a quantificar o valor atribuído aos diversos serviços, tendo em vista os diferentes níveis de prestação que podem ser oferecidos em cada serviço. As perguntas e respostas serão apresentadas a seguir, juntamente com um rápido comentário referente a cada item.

básico com cobertura de atendimento na casa do cliente com Hardware e Software inclusos. Classifica o contrato quanto à disponibilidade do serviço: normal (horário comercial) ou 24 horas por dia.

A pergunta 1.6 "Atendimento on-site: quanto você pagaria por atendimento técnico especializado?" considera o contrato básico com cobertura de atendimento na casa do cliente com Hardware e Software inclusos. Classifica o contrato quanto à especialização do técnico que efetuará o atendimento, estabelecendo se o mesmo é um técnico padrão normal ou especialista (possui experiência e domina o assunto).

A pergunta 1.7 "Atendimento on-site: quanto você pagaria por explicações detalhadas do problema?" considera o contrato básico com cobertura de atendimento na casa do cliente com Hardware e Software inclusos. Classifica o contrato quanto à

A pergunta 1.1 "Qual a mensalidade que você pagaria por um contrato de assistência técnica de Hardware e Software?" refere-se ao contrato de assistência técnica básico, que pode contemplar cobertura de Hardware e Softwa$r e$, sendo possível estabelecer três níveis para o tipo de atendimentos: (i) balcão - a pessoa leva seu equipamento até a empresa de assistência; (ii) telebusca - a empresa presta um serviço de busca e entrega; (iii) on-site - a empresa vai consertar o equipamento na casa do cliente.

A pergunta 1.2 "Atendimento on-site: que mensalidade você pagaria por contrato de Hardware ou Software?" refere-se ao tipo de cobertura desejado pelo cliente, considerando um atendimento em casa (on-site). Os três tipos de cobertura possíveis são: (i) o contrato tem cobertura de Hardware; (ii) o contrato tem cobertura de Software; (iii) o contrato tem cobertura de Hardware e Software.

A pergunta 1.3 "Atendimento on-site: que mensalidade você pagaria por atendimento rápido (lento)?" considera o contrato básico com cobertura de atendimento na casa do cliente com Hardware e Software inclusos. Classifica o atendimento quanto ao tempo que o cliente levaria para ser atendido; rápido (o técnico chega em 2 horas), normal (o técnico chega no próximo turno) e lento (o técnico chega em 24 horas).

A pergunta 1.4 "Quanto você pagaria por um atendimento com hora marcada?" considera o contrato básico com cobertura de atendimento na casa do cliente com Hardware e Software inclusos. Classifica o atendimento quanto à possibilidade de ser realizado com hora marcada ou não.

A pergunta 1.5 "Quanto você pagaria a mais por um serviço que atendesse nas 24 horas?" considera o contrato possibilidade de prestar ao cliente explicações simples (normais) ou detalhadas.

A pergunta 1.8 "Atendimento on-site: Qual mensalidade você pagaria?" refere-se a verificação de consistência das respostas anteriormente fornecidas pelos entrevistados. Esta avaliação é feita comparando-se um contrato com coberturas básicas ao contrato com coberturas básicas acrescido de várias características oferecidas anteriormente de forma individual.

$\mathrm{Na}$ seqüência, o grupo foi questionado em relação ao valor dos serviços complementares. A pergunta 2.1 "Que adicional você pagaria por um serviço de teleajuda de Hardware e Software?" questiona o valor do teleajuda, consistindo em um auxílio telefônico às pessoas que têm problemas com seus equipamentos. Esse atendimento poderia ser disponibilizado nos seguintes níveis: quanto ao tempo de disponibilidade, em horário comercial ou 24 horas; e quanto ao tempo de acesso permitido, uma hora por mês ou tempo livre de acesso.

A pergunta 2.2 "Qual o adicional que você pagaria por um serviço de treinamento?" questiona o valor atribuído a um serviço de treinamento em informática e computadores: treinamento inicial (uma única vez, duas horas de duração) ou continuado (uma a duas horas por mês, ao longo de todo o ano do contrato).

A pergunta 2.3 "Suporte na aquisição de $\mathrm{H} \& \mathrm{~S}-$ Qual o adicional que você pagaria?" questiona o valor atribuído ao suporte na aquisição de microcomputadores e periféricos, tais como Softwares, upgrades de Hardwares e outros. Os possíveis níveis de atendimento são: cotação apenas, projeto com cotação, e projeto com cotação pró-ativo (antecipa- 
Tabela 2: Valor percebido pelos serviços de assistência técnica.

\begin{tabular}{|c|c|c|c|c|c|c|c|c|c|}
\hline & 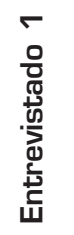 & 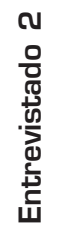 & 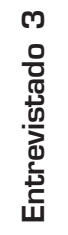 & 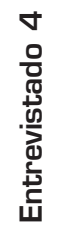 & 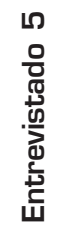 & 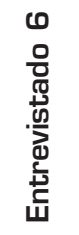 & 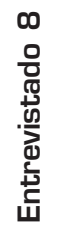 & 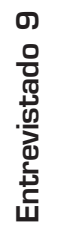 & $\begin{array}{l}\stackrel{\pi}{0} \\
\stackrel{\mathbb{U}}{\Sigma}\end{array}$ \\
\hline \multicolumn{10}{|l|}{ 1. Assistência Técnica } \\
\hline \multicolumn{10}{|c|}{ 1.1 Qual a mensalidade que você pagaria por contrato de assistência técnica H \& S? } \\
\hline Atendimento no Balcão & 10 & 5 & 5 & 5 & 1 & 8 & & 22 & 8,00 \\
\hline Atendimento com telebusca e entrega & 30 & 15 & 15 & 30 & 25 & 24 & & 28 & 23,83 \\
\hline Atendimento on-site & 20 & 30 & 30 & 15 & 40 & 30 & & 30 & 30,00 \\
\hline \multicolumn{10}{|c|}{ 1.2 Atendimento on-site: que mensalidade você pagaria por contrato parcial (H ou S)? } \\
\hline Hardware & 15 & 15 & 23 & 15 & 15 & 15 & & 20 & 16,85 \\
\hline Software & 5 & 15 & 7 & 15 & 15 & 15 & & 15 & 12,42 \\
\hline Hardware \& Software & 30 & 30 & 30 & 30 & 30 & 30 & 30 & 30 & 30,00 \\
\hline \multicolumn{10}{|c|}{ 1.3 Atendimento on-site: que mensalidade você pagaria por atendimento rápido (lento)? } \\
\hline Rápido (2 horas] & 35 & 40 & 40 & 35 & 40 & 40 & & 35 & 37,85 \\
\hline Normal (próximo turno] & 30 & 30 & 30 & 30 & 30 & 30 & 30 & 30 & 30,00 \\
\hline Lento (24 horas) & 25 & 10 & 25 & 25 & 10 & 30 & & 25 & 21,42 \\
\hline \multicolumn{10}{|c|}{1.4 Quanto você pagaria a mais por um atendimento com hora marcada? } \\
\hline Normal (no turno) & 30 & 30 & 30 & 30 & 30 & 30 & 30 & 30 & 30,00 \\
\hline Com hora marcada & 30 & 40 & 35 & 40 & 40 & 30 & & 35 & 35,71 \\
\hline \multicolumn{10}{|c|}{1.5 Quanto você pagaria a mais por um serviço que atendesse nas 24 horas? } \\
\hline Normal (horário comercial) & 30 & 30 & 30 & 30 & 30 & 30 & 30 & 30 & 30,00 \\
\hline 24 horas & 30 & 40 & 50 & 30 & 40 & 50 & & 40 & 40,00 \\
\hline \multicolumn{10}{|c|}{ 1.6 Atendimento on-site: quanto você pagaria pelo atendimento técnico especializado? } \\
\hline Normal & 30 & 30 & 30 & 30 & 30 & 30 & 30 & 30 & 30,00 \\
\hline Especialistas & 30 & 30 & 45 & 30 & 40 & 40 & & 35 & 35,71 \\
\hline \multicolumn{10}{|c|}{ 1.7 Atendimento on-site: quanto você pagaria por explicações detalhadas do problema? } \\
\hline Normal (explicações simples] & 30 & 30 & 30 & 30 & 30 & 30 & 30 & 30 & 30,00 \\
\hline Explicações detalhadas & 32 & 32 & 32 & 32 & 35 & 30 & & 35 & 33,28 \\
\hline \multicolumn{10}{|c|}{ 1.8 Atendimento on-site: verificação de consistência - Qual mensalidade você pagaria? } \\
\hline $\begin{array}{l}\text { Atendimento em } 24 \text { horas, sem hora marcada, } \\
\text { durante o horário comercial, prestado por } \\
\text { técnicos de nível médio, com explicações } \\
\text { simples sobre o problema }\end{array}$ & 30 & 30 & 28 & 30 & 30 & 30 & 40 & 28 & 30,75 \\
\hline $\begin{array}{l}\text { Atendimento em } 2 \text { horas, com a possibilidade } \\
\text { de hora marcada, durante as } 24 \text { horas, } \\
\text { prestado por técnicos especializados, com } \\
\text { explicações detalhadas }\end{array}$ & 45 & 55 & 60 & 50 & 50 & 60 & 60 & 50 & 53,75 \\
\hline
\end{tabular}


Tabela 3: Valor percebido pelos serviços complementares.

\section{Serviços Complementares}

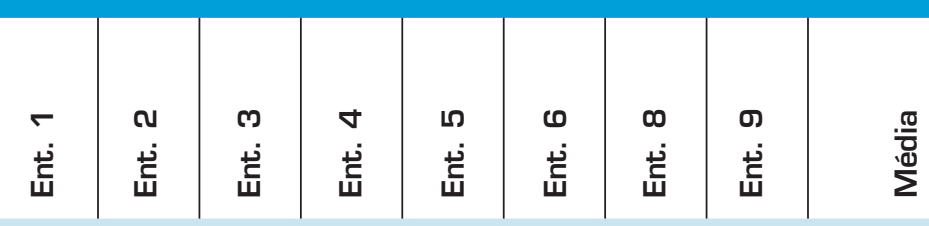

2.1 Teleajuda 051 - Que adicional você pagaria por um serviço de tele ajuda (H \& S)?

\begin{tabular}{|l|r|r|r|r|r|r|r|r|r|} 
Horário comercial, até 1 hora mensal & 1 & 0,5 & 1 & 1 & 1 & 2 & 0,5 & 2 & $\mathbf{1 , 1 2}$ \\
\hline Horário comercial, tempo livre de acesso & 2 & 1 & 3 & 2 & 3 & 3 & 5 & 2 & $\mathbf{2}, \mathbf{6 2}$ \\
\hline $\begin{array}{l}\text { Disponível 24 horas com até 1 hora de } \\
\text { uso por mês }\end{array}$ & 3 & 3 & 3 & 3 & 2 & 4 & 1 & 4 & $\mathbf{2 , 8 7}$ \\
\hline Disponível 24 horas e tempo livre de acesso & 6 & 4 & 8 & 4 & 6 & 5 & 10 & 6 & $\mathbf{6 , 1 2}$
\end{tabular}

2.2 Treinamento - Qual o adicional que você pagaria por um serviço de treinamento?

\begin{tabular}{|l|c|c|c|c|c|c|c|c|c|}
\hline $\begin{array}{l}\text { Treinamento básico no primeiro mês de } \\
\text { contrato, } 2 \text { horas de duração }\end{array}$ & 1,5 & 1 & 1,5 & 0,5 & 0,7 & 0 & 1,5 & 1,5 & $\mathbf{1 , 0 3}$ \\
\hline Treinamento continuado, 1 a 2 horas mês & 10 & 10 & 10 & 10 & 15 & 5 & 1 & 5 & $\mathbf{8 , 2 5}$
\end{tabular}

2.3 Suporte na aquisição de hardware e software - Qual o adicional que você pagaria?

\begin{tabular}{|l|r|r|r|r|r|r|r|r|r|} 
Cotação & 0,5 & 1 & 1 & 1 & 1 & 0,4 & 1 & 1 & $\mathbf{0 , 8 6}$ \\
\hline Projeto + Cotação & 1 & 2 & 3 & 2 & 3 & 0,5 & 3 & 2 & $\mathbf{2}, \mathbf{0 6}$ \\
\hline Projeto + Cotação + Pró-ativo & 1,5 & 3 & 5 & 3 & 5 & 1 & 5 & 3 & $\mathbf{3 , 3 1}$
\end{tabular}

2.4 Auto-ajuda - Que adicional você pagaria por acesso via Internet a banco de casos?

\begin{tabular}{|l|r|r|r|r|r|r|r|r|r|r}
\hline Auto-ajuda em Hardware & 0,1 & 0,1 & 0,3 & 0,5 & 0,1 & 0,4 & 0,1 & 1 & $\mathbf{0 , 3 2}$ \\
\hline Auto-ajuda em Software & 0,5 & 0,5 & 0,8 & 0 & 0,5 & 0,5 & 0,5 & 1 & $\mathbf{0 , 5 3}$ \\
\hline Auto-ajuda em Hardware e Software & 0,6 & 0,6 & 1 & 0,5 & 0,6 & 0,6 & 0,6 & 2 & $\mathbf{0 , 8 1}$
\end{tabular}

2.5 Que adicional você pagaria por uma assistência que também fornecesse instalação?

\begin{tabular}{|l|l|l|l|l|l|l|l|l|l|} 
Instalação de Hardware & 2 & 1 & 1 & 2 & 2 & 2 & 3 & 2 & $\mathbf{1 , 8 7}$ \\
\hline Instalação de Software & 3 & 1 & 1 & 0 & 3 & 0 & 2 & 1 & $\mathbf{1 , 3 7}$ \\
\hline Instalação de ambos & 5 & 2 & 2 & 2 & 5 & 2 & 5 & 3 & $\mathbf{3 , 2 5}$ \\
\hline Instalação de ambos com hora marcada & 5 & 2 & 2 & 2 & 5 & 2 & 5 & 4 & $\mathbf{3 , 3 7}$
\end{tabular}

2.6 Verificação de consistência - Qual mensalidade você pagaria?

\begin{tabular}{|c|c|c|c|c|c|c|c|c|c|}
\hline $\begin{array}{l}\text { PLANO A } \\
\text { Assistência técnica apenas }\end{array}$ & 30 & 30 & 30 & 30 & 30 & 30 & 30 & 30 & 20,00 \\
\hline $\begin{array}{l}\text { PLANO B } \\
\text { Assistência técnica, Teleajuda no horário } \\
\text { comercial, até } 1 \text { hora de uso, Treinamento } \\
\text { inicial H \& S, Suporte na cotação de H \& S }\end{array}$ & 40 & 35 & 35 & 40 & 45 & 35 & 40 & 30 & 38,12 \\
\hline $\begin{array}{l}\text { PLANO C } \\
\text { Assistência técnica, Teleajuda } 24 \text { horas, } \\
\text { tempo livre de acesso, Treinamento } 1 \text { a } 2 \\
\text { horas por mês, Suporte no projeto e cotação } \\
\text { de H \& S, Auto-ajuda via Internet, FAQs e } \\
\text { Bancos de caso H \& S, Suporte na instalação } \\
\text { de H \& S com hora marcada }\end{array}$ & 60 & 65 & 60 & 65 & 65 & 50 & 50 & 50 & 57,50 \\
\hline
\end{tabular}


ção das necessidades do cliente, no que se refere à expansão e atualização de equipamento).

A pergunta 2.4 "Auto-ajuda - Que adicional você pagaria por acesso via Internet a banco de casos?" questiona o valor atribuído pelos entrevistados a um serviço de autoajuda estilo banco de casos contendo resposta de perguntas mais freqüentes, que estaria disponível na Internet. Os níveis possíveis desse serviço são: ajuda em Hardware, ajuda em Software e ajuda em Hardware e Software.

A pergunta 2.5 "Que adicional você pagaria por uma assistência que também fornecesse instalação?" verifica o valor atribuído pelo cliente a um serviço de instalação, onde os níveis possíveis são: instalação de Hardware, instalação de Software, instalação de ambos e ainda instalação de ambos com hora marcada.

A pergunta 2.6 "Qual mensalidade você pagaria?" é uma pergunta que verifica a consistência das respostas anteriores. Essa pergunta apresenta três planos: o primeiro plano com cobertura básica; o segundo, com cobertura básica acrescida de alguns serviços complementares e um terceiro plano com cobertura básica acrescida de vários serviços complementares.

As Tabelas 2 e 3 contêm as respostas fornecidas pelos entrevistados ao conjunto de questões. Vale esclarecer que as respostas que aparecem nas colunas dos entrevistados 1 a 9 , assim como a média geral, representam o valor percebido pelo cliente, obtido durante os estudos em grupos focados. Os valores estão expressos em R $\$$ (Reais).

\section{Modelo matemático para o valor percebido}

Uma vez definido o valor atribuído pelo cliente para os diversos atributos e seus respectivos níveis, os próximos passos contemplam estabelecer um modelo matemático para o valor percebido pelo cliente e para os custos dos serviços, conforme será detalhado a seguir.

Para tanto, inicialmente, os níveis de qualidade $X_{1}$ a $X_{k}$ devem ser convertidos para uma escala padronizada, $Z_{1}$ a $Z_{k}$. O intervalo de valores para $Z_{1}$ a $Z_{k}$ é $[-1 ; 1]$, apesar de muitos variarem apenas no intervalo positivo, ou seja, [0; 1]. As fórmulas de conversão utilizadas no estudo de caso aparecem na Tabela 4.

Vale dizer que a fórmula de conversão de $X_{\mathrm{i}}=>Z_{\mathrm{i}} \mathrm{em}$ geral é não linear, pois o valor atribuído pelo cliente a um certo atributo em geral não é linearmente proporcional ao nível deste atributo. Essas fórmulas de conversão foram obtidas utilizando rotinas de regressão não linear. Essas rotinas foram aplicadas aos dados obtidos no estudo em grupo focalizado. Para o ajuste dos coeficientes, foi utilizado o programa Statgraphics versão 7.0.

Em seguida, estabelece-se o modelo matemático, definindo a sua estrutura geral. De maneira geral, o modelo irá contemplar termos aditivos e multiplicativos, conforme a própria relação dos atributos entre si. Para o estudo de caso em questão, o modelo construído foi:

Valor percebido $=\mathrm{Z}_{1} \mathrm{Z}_{2}\left(\mathrm{C}_{1}+\mathrm{C}_{3} \mathrm{Z}_{3}+\mathrm{C}_{4} \mathrm{Z}_{4}+\mathrm{C}_{5} \mathrm{Z}_{5}+\mathrm{C}_{6} \mathrm{Z}_{6}+\mathrm{C}_{7} \mathrm{Z}_{7}\right)$

$$
+\mathrm{C}_{8} \mathrm{Z}_{8} \mathrm{Z}_{9}+\mathrm{C}_{10} \mathrm{Z}_{10}+\mathrm{C}_{11} \mathrm{Z}_{11}+\mathrm{C}_{12} \mathrm{Z}_{12}+
$$$$
\mathrm{Z}_{13}\left(\mathrm{C}_{13}+\mathrm{C}_{14} \mathrm{Z}_{14}\right)
$$

Tabela 4: Atributos, fórmula de conversão e intervalo de valores para $X$.

\begin{tabular}{|c|c|c|}
\hline Atributo & Fórmula de conversão & Valores para $\mathrm{X}$ \\
\hline Tipo de atendimento & $Z_{1}=X_{1}$ & Balcão $=0,27$, Telebusca $=0,79 ;$ On-site $=1,0$ \\
\hline Tipo de cobertura & $Z_{2}=X_{2}$ & Hardware $=0,56 ;$ Software $=0,41 ;$ H\&S $=1,0$ \\
\hline Velocidade de atendimento & $Z_{3}=0,84 \times \operatorname{Ln}\left(6,6 / X_{3}\right)$ & 2 a 24 horas \\
\hline Assistência com hora marcada & $Z_{4}=X_{4}$ & $0=$ não, $1=\operatorname{sim}$ \\
\hline Disponibilidade 24 horas & $Z_{5}=\left[X_{5}-8\right) / 16$ & 8 a 24 horas \\
\hline Qualificação dos técnicos & $Z_{6}=2 \times\left(X_{6}-0,5\right)$ & 0 = baixa, 1 = alta \\
\hline Explicações detalhadas & $Z_{7}=X_{7}$ & $0=$ não, $1=\operatorname{sim}$ \\
\hline Disponibilidade de teleajuda & $Z_{8}=\left(X_{8} / 24\right)^{0,8}$ & 0 a 24 horas/dia \\
\hline Tempo de acesso ao teleajuda & $Z_{g}=\left(X_{g} / 20\right)^{0,25}$ & 1 a 20 horas/mês \\
\hline Treinamento & $Z_{10}=\left(X_{10} / 24\right)^{0,6}$ & 0 a 24 horas/ano \\
\hline Suporte na aquisição & $Z_{11}=X_{11}$ & $\begin{array}{l}\text { Nenhum = 0; Cotação = 0,26; Cotação + Projeto } \\
=\text { 0,62; Cotação + Projeto + Pró-ativo }=1\end{array}$ \\
\hline Auto-ajuda via Internet & $Z_{12}=X_{12}$ & $\begin{array}{l}\text { Nenhuma }=0 ; \text { Hardware = 0,39; } \\
\text { Software = 0,65; H\&S = } 1\end{array}$ \\
\hline Instalação de Hardware e Software & $Z_{13}=X_{13}$ & $\begin{array}{l}\text { Sem suporte }=0 ; \text { Hardware = 0,58; } \\
\text { Software = 0,42; H \& S = } 1\end{array}$ \\
\hline Instalação com hora marcada & $Z_{14}=X_{14}$ & $0=$ não, $1=\operatorname{sim}$ \\
\hline
\end{tabular}


Os termos aditivos e multiplicativos, ou seja, a função ajustada respeita a natureza do serviço que está sendo modelado. Por exemplo, a assistência técnica propriamente dita é representada pelos termos $\mathrm{Z}_{1}$ e $\mathrm{Z}_{2}$, onde $\mathrm{Z}_{1}$ é o tipo de atendimento (on-site, balcão,...) e $Z_{2}$ é o tipo de cobertura (hardware, software,...). Assim, os termos $\mathrm{Z}_{3}$ (velocidade de atendimento), $\mathrm{Z}_{4}$ (assistência com hora marcada), $Z_{5}$ (disponibilidade 24 horas), $Z_{6}$ (qualificação dos técnicos) e $Z_{7}$ (assistência prestando explicações detalhadas) aparecem em uma posição multiplicativa, pois nenhum desses atributos pode agregar valor se a própria assistência técnica não for prestada. Eles não existem sem a assistência técnica.

Por outro lado, termos como $\mathrm{Z}_{10}$ (treinamento), $\mathrm{Z}_{11}$ (suporte na aquisição de $\mathrm{H} \& \mathrm{~S}$ ) e $\mathrm{Z}_{12}$ (auto-ajuda via Internet) aparecem numa posição aditiva, pois podem ser oferecidos (podem agregar valor) mesmo se a assistência técnica não for oferecida. São serviços complementares, que guardam independência em relação aos demais termos.

Por fim, $\mathrm{Z}_{8}$ e $\mathrm{Z}_{9}$ devem ser multiplicados, pois correspondem ao tempo e disponibilidade do teleajuda, sendo que um não agrega nenhum valor se o outro estiver ausente (de nada adianta um serviço de teleajuda "disponível" zero horas por dia). Similarmente, a instalação com hora marcada $\left(Z_{14}\right)$ depende da existência do serviço de instalação de software e hardware $\left(Z_{13}\right)$. Sendo assim, $Z_{14}$ guarda uma relação multiplicativa com $\mathrm{Z}_{13}$.

Vale esclarecer que os termos dependência / independência usados nos parágrafos anteriores referem-se à dependência / independência técnica entre os serviços ofertados (a existência de um serviço depende / independe da existência do outro). Eles não se referem à dependência / independência estatística, que seria uma outra consideração.

Os valores dos coeficientes do modelo, $\mathrm{C}_{1}, \ldots, \mathrm{C}_{14}$, foram definidos a partir das informações reunidas na etapa 3 anteriormente citada. Os resultados aparecem sumarizados na Tabela 5. Vale esclarecer que a construção do modelo matemático exige o domínio de técnicas de regressão não linear. Assim, a modelagem exige tanto pessoas com conhecimento técnico sobre o serviço prestado como pessoas que detenham conhecimento de técnicas estatísticas. Os detalhes da regressão múltipla não linear fogem ao escopo deste trabalho, mas podem ser vistos em Montgomery \& Peck (1992) e Bates \& Watts (1988).

O uso da equação (1), conjuntamente com os coeficientes apresentados na Tabela 5, permite boa aderência aos dados coletados no grupo focalizado. $\mathrm{O}$ valor de $\mathrm{R}^{2}$ para os serviços de assistência técnica é igual a 0,941, enquanto que para os serviços complementares é igual a 0,951. Utilizando a equação (1) é possível estimar o valor percebido para qualquer combinação de serviços e correspondentes níveis de atendimento.

Conforme sugestão de um dos revisores do artigo, a modelagem poderia ser feita utilizando modelos de preferência declarada, os quais, em geral, apóiam-se no uso de regressão logística. A regressão logística, por sua vez, é um caso particular de regressão não linear e, portanto, estaria contemplada no método proposto neste artigo. Detalhes da técnica de preferência declarada podem ser vistos em Ortúza e Willumsen (1994).

\section{Modelo matemático para o custo dos serviços}

\section{Levantamento dos custos dos serviços}

Para efetuar-se o levantamento dos custos foram considerados os dados obtidos junto ao setor de operações da empresa, os dados de fabricantes de Hardware e Software, os dados médios dos gastos dos últimos doze meses da

Tabela 5: Coeficientes para o modelo do valor percebido.

\begin{tabular}{|c|r|l|}
\hline Coeficiente & Valor & \multicolumn{1}{c|}{ Associado aos atributos } \\
\hline$C_{1}$ & 30,00 & Tipo de atendimento e Tipo de cobertura \\
\hline$C_{3}$ & 8,09 & Velocidade de atendimento \\
\hline$C_{4}$ & 4,01 & Assistência com hora marcada \\
\hline$C_{5}$ & 6,23 & Disponibilidade 24 horas \\
\hline$C_{6}$ & 6,80 & Qualificação dos técnicos \\
\hline$C_{7}$ & 2,68 & Explicações detalhadas \\
\hline$C_{8}$ & 8,95 & Disponibilidade de teleajuda e Tempo de acesso ao teleajuda \\
\hline$C_{10}$ & 6,16 & Treinamento \\
\hline$C_{11}$ & 3,62 & Suporte na aquisição \\
\hline$C_{12}$ & 1,24 & Auto-ajuda via Internet \\
\hline$C_{13}$ & 4,60 & Instalação de Hardware e Software \\
\hline$C_{14}$ & 0,15 & Instalação com hora marcada \\
\hline
\end{tabular}


empresa e os dados de bens, serviços e equipamentos que deveriam ser utilizados para efetuar os serviços. Para efeito do cálculo dos insumos utilizados (bens, serviços e equipamentos), foram considerados preços de mercado; bens com valores mais elevados foram amortizados em 12 ou 24 meses. A empresa utiliza-se do sistema de absorção parcial de custos para cálculo do custo dos serviços.

Para que os custos pudessem ser devidamente alocados, foram observadas as seguintes considerações iniciais:

- quantidade de contratos - foram estimados 1.000 clientes com contratos;

- assistências possíveis - para esse cálculo foi observado o tempo médio entre falhas declarado pelos fabricantes e a experiência da empresa;

- quantidade mensal - com base na quantidade de contratos e no número de assistências possíveis calculou-se o nú- mero de chamados técnicos mensais;

- produtividade - obtido com base nos dados de produtividade técnica média;

- recursos humanos - o número de técnicos alocados foi obtido a partir da produtividade de cada técnico da empresa e do tempo médio entre falhas dos fabricantes e da empresa.

Essas condições iniciais refletem a situação atual da empresa. Cada item levantado está associado com o seu correspondente no levantamento dos valores percebidos, ou seja, para um determinado tipo de serviço requerido pelo cliente foi calculado qual o custo do mesmo para a empresa. Os resultados aparecem na Tabela 6.

No cenário do cálculo dos custos dos serviços complementares (ver Tabela 7), novamente foram consideradas algumas hipóteses:

Tabela 6: Custo dos serviços de assistência técnica.

1 Assistência Técnica

Valores calculados

1.1 Custo mensal de um contrato de assistência técnica (H \& S)

Atendimento no Balcão

Atendimento com telebusca e entrega

20,80

Atendimento on-site

24,77

33,80

1.2 Custo do atendimento on-site, conforme o tipo de contrato

Hardware

9,85

Software

22,43

Hardware \& Software

33,80

1.3 Custo do atendimento on-site, conforme a velocidade de atendimento

Rápido (2 horas]

Normal

41,01

Lento (24 horas)

33,80

30,96

1.4 Custo do atendimento com hora marcada

Normal (no turno)

Com hora marcada

33,80

41,01

1.5 Custo do serviço, conforme o turno de atendimento Normal (horário comercial)

24 horas

33,80

39,95

1.6 Custo do atendimento on-site, conforme o padrão dos técnicos Normal

Especialistas

33,80

40,23

1.7 Custo do atendimento on-site, conforme o nível de explicações fornecidas Normal (Explicações simples)

Explicações detalhadas

33,80

41,62

1.8 Custo do atendimento on-site, conforme opções a seguir: Atendimento em 24 horas, sem hora marcada, durante o horário comercial, prestado por técnicos de nível médio, com explicações simples sobre o problema

Atendimento em 2 horas, com a possibilidade de hora marcada, durante as 24 horas, prestado por técnicos especializados, com explicações detalhadas 
- quantidade de contratos - foi estimado o mesmo número utilizado nos serviços de assistência técnica;

- tempo do serviço - para esse cálculo foi observado o tempo médio dos serviços propostos e, com base nesse tempo, o número de atendimentos;

- quantidade de atendimentos - com base na quantidade de contratos e na quantidade de atendimentos possíveis calculou-se o número de atendimentos mensais;

- produtividade - com base nos dados de produção dos técnicos, obteve-se quantos atendimentos cada técnico pode efetuar mensalmente;
- recursos humanos - o número de técnicos alocados foi obtido da produtividade de cada técnico da empresa e do tempo médio entre falhas dos computadores;

- estimativa de atendimentos - nos serviços que a empresa tinha similar foi pesquisada a base de tempos do similar. Nos serviços que a empresa não possuía foi feita estimativa com base na experiência de empresas parceiras que foram consultadas.

\section{Modelo matemático}

A modelagem do custo dos serviços segue basicamente a

Tabela 7: Custo dos serviços complementares.

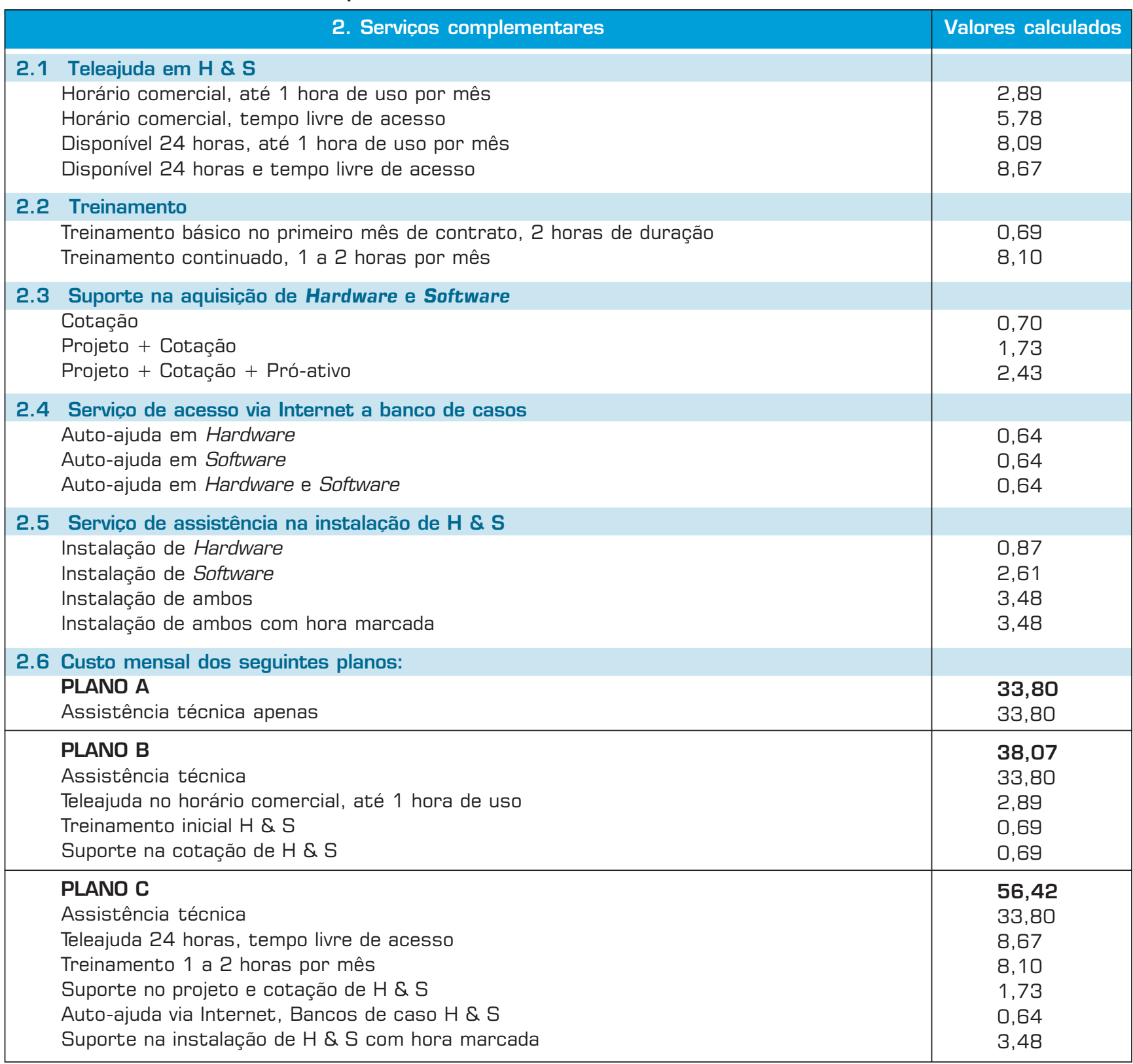


mesma orientação utilizada na modelagem do valor percebido. A diferença é que o valor percebido é obtido a partir das informações do grupo focalizado (clientes), enquanto que os custos são calculados pela equipe técnica. Vale ressaltar que, neste trabalho, o levantamento dos custos foi realizado utilizando-se o sistema de absorção parcial de custos. Todos os dados foram fornecidos pela empresa.

$\mathrm{Na}$ construção do modelo de custos, foi utilizada a mesma forma funcional adotada na modelagem do valor percebido, ou seja:

Custo do serviço $=\mathrm{Z}_{1} \mathrm{Z}_{2}\left(\mathrm{C}_{1}+\mathrm{C}_{3} \mathrm{Z}_{3}+\mathrm{C}_{4} \mathrm{Z}_{4}+\mathrm{C}_{5} \mathrm{Z}_{5}+\mathrm{C}_{6} \mathrm{Z}_{6}+\mathrm{C}_{7} \mathrm{Z}_{7}\right)$ $+C_{8} Z_{8} Z_{9}+C_{10} Z_{10}+C_{11} Z_{11}+C_{12} Z_{12}+$ $\mathrm{Z}_{13}\left(\mathrm{C}_{13}+\mathrm{C}_{14} \mathrm{Z}_{14}\right)$

Os atributos $X_{1}$ a $X_{k}$ são exatamente os mesmos descritos anteriormente. As fórmulas de conversão $\mathrm{Xi}=>\mathrm{Zi}$ mudam um pouco, na medida em que o custo associado aos diferentes níveis de um atributo não segue necessariamente a mesma curva obtida para o valor percebido. As fórmulas de conversão $X_{\mathrm{i}}=>Z_{\mathrm{i}}$ para o modelo de custo aparecem na Tabela 8.

Os coeficientes do modelo de custo são diferentes daqueles utilizados no modelo de valor percebido. A Tabela 9 apresenta os coeficientes obtidos no estudo de caso. O uso da equação (2), conjuntamente com os coeficientes apresentados na Tabela 9, modela com precisão os custos calculados pela equipe técnica $\left(R^{2}=0,99\right)$. Utilizando a equação (2) é possível estimar o custo de qualquer combinação de serviços e correspondentes níveis de atendimento. É importante escla- recer que a forma funcional dos modelos de valor percebido e custo não precisa ser a mesma. Nesse estudo foi utilizada a mesma forma porque forneceu boa aderência aos dados.

\section{Comparação entre valor percebido e custo}

Obtidos os modelos para valor percebido e custo dos serviços, é possível comparar esses dois elementos. Essa comparação irá permitir uma análise do potencial de lucro. A partir dessa análise é possível estabelecer algumas conclusões, como, por exemplo: quais serviços deveriam ser incentivados, quais deveriam ter seus custos trabalhados ou ainda quais poderiam ser descontinuados.

A tabela 10 efetua esse comparativo. A estimativa do potencial de lucro considerando o valor percebido pelo cliente permite que a empresa realize seu planejamento mantendo o foco no cliente.

\section{Açoes empresariais}

O potencial de lucro, explicitado na Tabela 10 permitiu à empresa estabelecer várias ações, conforme será detalhado a seguir:

- O mix de serviços de assistência técnica que poderiam trazer maior lucratividade para a empresa seria: serviço on-site, prestado com velocidade e contando com instalação e suporte na aquisição de hardware e software. Esses foram os elementos que se destacaram com potencial de lucro positivo. Os técnicos da empresa que participaram conjuntamente da atividade de elaborar o cálculo de

Tabela 8: Atributos, fórmulas de conversão e valores para $\mathrm{X}$.

\begin{tabular}{|c|c|c|}
\hline Atributo & Fórmula de conversão & Valores para X \\
\hline Tipo de atendimento & $Z_{1}=X_{1}$ & Balcão $=0,62$, Telebusca $=0,73 ;$ On-site $=1,0$ \\
\hline Tipo de cobertura & $Z_{2}=X_{2}$ & Hardware = 0,23; Software = 0,66; H \& S = 1,0 \\
\hline Velocidade de atendimento & $Z_{3}=0,91 \times \operatorname{Ln}\left(6,0 / X_{3}\right)$ & 2 a 24 horas \\
\hline Assistência com hora marcada & $Z_{4}=X_{4}$ & $0=$ não, $1=\operatorname{sim}$ \\
\hline Disponibilidade 24 horas & $Z_{5}=\left(X_{5}-8\right) / 16$ & 8 a 24 horas \\
\hline Qualificação dos técnicos & $Z_{6}=2 \times\left(X_{6}-0,5\right)$ & $0=$ baixa, $1=$ alta \\
\hline Explicações detalhadas & $\mathrm{Z}_{7}=\mathrm{X}_{7}$ & 0 = não, $1=\operatorname{sim}$ \\
\hline Disponibilidade de teleajuda & $Z_{8}=\left[X_{8} / 24\right]^{0,35}$ & 0 a 24 horas/dia \\
\hline Tempo de acesso ao teleajuda & $Z_{g}=\left(X_{g} / 20\right)^{0,21}$ & 1 a 20 horas/mês \\
\hline Treinamento & $Z_{10}=X_{10} / 24$ & 0 a 24 horas/ano \\
\hline Suporte na aquisição & $Z_{11}=X_{11}$ & $\begin{array}{l}\text { Nenhum = 0; Cotação = 0,29; Cotação + Projeto } \\
=0,71 ; \text { Cotação + Projeto + Pró-ativo }=1\end{array}$ \\
\hline Auto-ajuda via Internet & $Z_{12}=X_{12}$ & $\begin{array}{l}\text { Nenhuma }=0 ; \text { Hardware }=0,83 \\
\text { Software }=0,88 ; \text { H \& S }=1\end{array}$ \\
\hline Instalação de H \& S & $Z_{13}=X_{13}$ & $\begin{array}{l}\text { Sem suporte }=0 ; \text { Hardware }=0,25 ; \\
\text { Software }=0,75 ; \text { H \& S }=1\end{array}$ \\
\hline Instalação com hora marcada & $Z_{14}=X_{14}$ & $0=$ não, $1=\operatorname{sim}$ \\
\hline
\end{tabular}


custos entenderam, em função dos resultados do grupo focalizado, que os mesmos são serviços fortemente valorizados pelos clientes. Os setores de marketing e de operações tomaram a decisão de priorizar esses serviços em suas ações. Os dois departamentos concluíram que devem trabalhar para melhor explorar esses serviços, através do estabelecimento de uma estratégia conjunta;

- Opcionalmente, para os clientes que não desejarem o atendimento on-site, o serviço de telebusca será oferecido, pois ele também revela um forte potencial de lucro;

- Após a análise da Tabela 10, a empresa decidiu suspender os serviços de assistência técnica com hora marcada e de instalação com hora marcada, pois eles apresentam potenciais de lucro negativos (são pouco valorizados pelo cliente). No médio prazo, essa ação poderá ser revista, desde que os custos do atendimento com hora marcada possam ser reduzidos a níveis compatíveis com as percepções dos clientes;

- Por fim, a empresa descartou as implementações dos serviços complementares explicações detalhadas e treinamento, uma vez que eles apresentam potenciais negativos. Vale comentar que poderia ser feita uma associação com outra empresa, que tivesse como foco treinamento. Tal parceria poderia viabilizar a exploração conjunta desses serviços.

Por fim, vale comentar as vantagens e desvantagens do uso da modelagem proposta na empresa em questão. A principal vantagem observada refere-se ao conhecimento das necessidades do cliente, a ser utilizado no apoio às

Tabela 9: Coeficientes para o modelo de custo do serviço.

\begin{tabular}{|c|r|l|}
\hline Coeficiente & Valor & \multicolumn{1}{c|}{ Associado aos atributos } \\
\hline$C_{1}$ & 33,80 & Tipo de atendimento e Tipo de cobertura \\
\hline$C_{3}$ & 4,56 & Velocidade de atendimento \\
\hline$C_{4}$ & 4,56 & Assistência com hora marcada \\
\hline$C_{5}$ & 3,89 & Disponibilidade 24 horas \\
\hline$C_{6}$ & 4,06 & Qualificação dos técnicos \\
\hline$C_{7}$ & 4,06 & Explicações detalhadas \\
\hline$C_{8}$ & 8,67 & Disponibilidade de teleajuda e Tempo de acesso ao teleajuda \\
\hline$C_{10}$ & 8,10 & Treinamento \\
\hline$C_{11}$ & 2,43 & Suporte na aquisição \\
\hline$C_{12}$ & 0,73 & Auto-ajuda via Internet \\
\hline$C_{13}$ & 3,48 & Instalação de Hardware e Software \\
\hline$C_{14}$ & 0,12 & Instalação com hora marcada \\
\hline
\end{tabular}

Tabela 10: Potencial de lucro estimado no estudo de caso.

\begin{tabular}{|l|c|c|c|}
\hline \multicolumn{1}{|c|}{ Niveis de atendimento } & Valor percebido & Custo do serviço & Potencial de lucro \\
\hline On-site (x Balcão) & 21,90 & 14,53 & 7,37 \\
\hline Telebusca (x Balcão) & 15,60 & 9,46 & 6,14 \\
\hline Velocidade de atendimento & 16,18 & 14,42 & 1,76 \\
\hline Suporte na aquisição & 3,62 & 2,43 & 1,19 \\
\hline Instalação de Hardware e Software & 4,60 & 3,48 & 1,12 \\
\hline Qualificação dos técnicos & 13,60 & 12,86 & 0,74 \\
\hline Auto-ajuda via Internet & 1,24 & 0,64 & 0,60 \\
\hline Teleajuda & 8,95 & 8,67 & 0,28 \\
\hline Disponibilidade 24 horas & 6,23 & 6,15 & 0,08 \\
\hline Treinamento (horas por ano) & 6,16 & 8,10 & $-1,94$ \\
\hline Instalação com hora marcada & 0,15 & 3,48 & $-3,33$ \\
\hline Explicaçães detalhadas & 2,68 & 8,81 & $-6,13$ \\
\hline Assistência com hora marcada & 4,01 & 14,42 & 10,41 \\
\hline
\end{tabular}


decisões gerenciais. Neste sentido, a modelagem foi extremamente útil. Os resultados foram integralmente utilizados pela empresa no planejamento de investimentos e reformulação de serviços, conforme mencionado anteriormente. Entre as desvantagens da modelagem proposta, foi observado o seguinte: (i) os estudos em grupos focados exigem um pequeno investimento em termos financeiros, associado principalmente às horas-homens mobilizadas no planejamento do estudo; (ii) a modelagem matemática exige profissionais com domínio de técnicas estatísticas, os quais não estão disponíveis no corpo da empresa.

\section{CONCLUSÕES}

Este trabalho apresentou uma proposta para a modelagem do valor percebido pelos clientes de empresas prestadoras de serviços. A abordagem proposta é composta das seguintes etapas: (i) estudo em grupo focalizado para levantar os atributos que o cliente valoriza; (ii) levantamento dos níveis de qualidade associados a cada atributo; (iii) levantamento do valor atribuído pelo cliente aos diferentes níveis de prestação de serviço; (iv) modelagem matemática do valor percebido; (v) levantamento e modelagem matemática dos custos associados aos diferentes níveis de serviço; (vi) comparação entre o valor percebido e os custos das diferentes modalidades de serviços e níveis de atendimento que podem ser oferecidos; e (vii) planejamento de ações: serviços a serem explorados, serviços que devem sofrer um trabalho de redução de custos e serviços a serem eliminados do mix.
O modelo proposto estabelece uma relação simples entre o valor percebido pelo cliente e os custos relacionados aos serviços que podem ser oferecidos. A pesquisa e levantamento do valor percebido pelo cliente e, mais ainda, a inclusão explícita do valor percebido na modelagem conduz a uma melhor adaptação da empresa ao mercado em que atua, otimizando os esforços na busca de maior lucratividade. Devido à generalidade das etapas que compõem a abordagem proposta, acredita-se que ela possa ser utilizada em muitos segmentos da indústria de serviços.

A modelagem foi apresentada através de um estudo de caso realizado junto a uma empresa prestadora de serviços de manutenção em microcomputadores. Na medida em que a modelagem proposta conduz à avaliação do potencial de lucro, ela estabelece uma base sólida para a tomada de decisão. Assim, foi possível identificar: (i) serviços com alto potencial de lucro, que devem ser explorados e servir de ponto de marketing; (ii) serviços considerados essenciais, que não apresentam potencial de lucro positivo, os quais devem ser objeto de um trabalho de redução de custos; e (iii) serviços considerados supérfluos, que não apresentam potencial de lucro positivo.

As organizações voltadas a ouvir o cliente podem alcançar uma vantagem competitiva utilizando a abordagem proposta. Ela pode ser usada para subsidiar as decisões referentes a investimentos a serem efetuados, serviços a serem desenvolvidos, serviços a serem descontinuados, etc. A abordagem proposta permite que as decisões sejam tomadas a partir da ótica da engenharia de produção, buscando continuamente a melhor relação custo benefício para as empresas e seus parceiros, entre os quais se destaca o próprio cliente.

- Referências bibliográficas

ALBRECHT, K. 1992. Revolução nos serviços. São Paulo, Pioneira, $254 \mathrm{p}$

AUSTIN, R. 2000. Rapid response. The Professional Journal, jul.:16-19.

BARCELLOS, P.F.P. 1999. Satisfação do Cliente e Desempenho Empresarial. Apostila da disciplina de gerência de serviços, Porto Alegre, PPGEP/UFRGS.

BATES, D.M. \& WATTS, D.G. 1988. Nonlinear regression analysis and its applications. New York, Wiley.

BENNEKOM, F. 2000. Butterfly Economics: a new general theory of social and economic behavior. The Professional Journal, jul.: 60-63.
BERRY, L. \& PARASURAMAN, A. 1992. Serviços de marketing; competindo através da qualidade. São Paulo, Maltese-Norma, $238 \mathrm{p}$.

BEYEA, S. \& NICOLL, L.H. 2000. Methods to conduct focus group and the moderator's rule. Association of Operating Room Nurses Journal. Denver, 71(5):10671068 .

CARLZON, J. 1994. A hora da verdade. 10. ed. Rio de Janeiro, COP, 120 p.

EDVINSSON, L. \& MALONE, M. 1998. Capital intelectual. São Paulo, Makron, 214 p.
GRÖNROOS, C. 1996. Relationship marketing: strategic and tactical implications. Management Decision, 34(3): 5-14.

FISHER, C. \& SALIBA, M. 2000. Managing customer value. Quality Progress, 33(6): 63- 69.

GUSTAFSSON, A. \& JOHNSON, M. 1997. Bridging the quality-satisfaction gap. Quality Management Journal, 4(3): 27-43.

GUSTAFSSON, A. \& JOHNSON, M. 1997. Bridging the quality-satisfaction gap II: measuring and prioritizing customer needs. In: The Third Annual International QFD Symposium,

Linköping, Anais, 2: 21-34.
MONTGOMERY, D.C. \& PECK, E.A. 1992. Introduction to linear regression analysis. New York, John Wiley \& Sons, 527p.

ORTÚZA, J.D. \& WILLUMSEN, L.G. 1994 Modelling Transports. 4. ed. New York, John Wiley \& Sons.

PRAHALAD, C.K. \& RASMAWANY, V. 2000. Como incorporar as competências do cliente. HSM Management, maio/jun.: 42-57.

RIBEIRO, J.L. \& RUPPENTHAL, C. 2000. Grupos Focalizados: Revisão e Emprego na engenharia de produção. Caderno Técnico, PPGEP/UFRGS, Porto Alegre RS, 12 p. 